\title{
COMMON FIXED POINT THEOREMS ON SPACES WITH VECTOR-VALUED $B$-METRICS
}

\author{
S. BAZINE, A. ALIOUCHE, AND F. ELLAGGOUNE
}

Received 15 April, 2014

\begin{abstract}
The purpose of this paper is to prove common fixed point theorems for two operators without the assumption of continuity on a set endowed with vector-valued $b$-metric and we also study the case of two vector-valued $b$-metrics. The well-posedness of the fixed point problem is also discussed and an application is presented for systems of operator equations in complete $b$-normed vector space. Our results improve and generalize theorems 2 and 5 of M. Boriceanu [5].
\end{abstract}

2010 Mathematics Subject Classification: 37C25; 47H10; 54H25

Keywords: fixed point, generalized $b$-metric space, matrix convergent to zero, sequence of successive approximations

\section{INTRODUCTION}

The classical Banach contraction principle was extended for contraction mappings on spaces endowed with vector-valued metrics by Perov [9] in 1964. In [2] Bakhtin introduced the notion of $b$-metric spaces as a generalization of metric spaces and this notion was extensively used by Czerwik in [6]. Bakhtin proved the contraction mapping principle in $b$-metric spaces that generalized the famous Banach contraction principle in metric spaces. Since then, several papers have dealt with fixed point theory or the variational principle for single-valued operators in $b$-metric spaces see V. Berinde [3]. In the first section, we prove some results for two operators on a generalized $b$-metric space without the assumption of continuity that has been used in theorem 2 of M. Boriceanu [5] and the well-posedness of the fixed point problem is also discussed. As an application we present a theorem for systems of operator equations in complete $b$-normed vector space and in the second section we generalize theorem 5 given by M. Boriceanu [5] using two generalized $b$-metrics.

The first author was supported in part by the research project CNEPRU, Grant No. B01520130004. 


\section{BASIC DEFINITIONS AND AUXILIARY RESULTS}

The aim of this section is to present some definitions and results that will be needed in the sequel.

Definition 1. [6] Let $X$ be a nonempty set and let $s \geq 1$ be a given real number. A function $d: X \times X \rightarrow \mathbb{R}_{+}^{n}$ is said to be a vector-valued $b$-metric on $X$ if and only if for all $x, y, z \in X$ the following conditions are satisfied:

(1) $d(x, y)=0$ if and only if $x=y$,

(2) $d(x, y)=d(y, x)$,

(3) $d(x, z) \leq s[d(x, y)+d(y, z)]$.

A pair $(X, d)$ is called a generalized $b$-metric space.

Remark 1. If $\alpha, \beta \in \mathbb{R}^{n}$ with $\alpha=\left(\alpha_{1}, \alpha_{2}, \ldots, \alpha_{n}\right), \beta=\left(\beta_{1}, \beta_{2}, \ldots, \beta_{n}\right)$ and $c \in \mathbb{R}$, then by $\alpha \leq \beta$ (respectively $\alpha<\beta$ ), we mean that $\alpha_{i} \leq \beta_{i}$ (respectively $\alpha_{i}<\beta_{i}$ ), for all $i=\overline{1, n}$ and by $\alpha \leq c$ we mean that $\alpha_{i} \leq c$, for all $i=\overline{1, n}$.

The advantage for using a $b$-metric is that it allows us to obtain concrete results, not only regarding the existence of the fixed point, but also regarding the convergence of sequences of successive approximations, data dependence of the fixed point set and the study of well-posedness of the fixed point problem.

Notice that in a generalized $b$-metric space $(X, d)$ the notions of convergent sequence, Cauchy sequence, completeness, compactness, open and closed subset are similar to those for usual metric spaces, but in general a generalized $b$-metric function $d$ is not continuous, for examples, see [8].

Throughout this paper we denote by $\mathcal{M}_{n \times n}\left(\mathbb{R}_{+}\right)$the set of all $n \times n$ matrices with positive elements, by $\Theta$ the zero $n \times n$ matrix and by $I$ the identity $n \times n$ matrix. Notice also that, for the sake of simplicity, we will make an identification between row and column vectors in $\mathbb{R}^{n}$.

Definition 2. [14] A matrix $C \in \mathcal{M}_{n \times n}\left(\mathbb{R}_{+}\right)$is said to be convergent to zero if and only if

$$
C^{n} \rightarrow \Theta, \quad \text { as } n \rightarrow \infty .
$$

For other examples and considerations on matrices which converge to zero, see Turinici [13].

Notice that, for the proof of the main results, we need the following theorem, part of which being a classical result in matrix analysis, see [10,11].

Theorem 1. [10] Let $C \in \mathcal{M}_{n \times n}\left(\mathbb{R}_{+}\right)$. The following statements are equivalent:

i) $C$ is a matrix convergent to zero,

ii) the matrix $(I-C)$ is nonsingular and

$$
(I-C)^{-1}=I+C+C^{2}+\ldots+C^{n}+\ldots,
$$

iii) the matrix $(I-C)$ is nonsingular and $(I-C)^{-1}$ has nonnegative elements. 
Lemma 1. [6] Let $(X, d)$ be a generalized b-metric space and let $\left\{x_{k}\right\}_{k=0}^{n} \subset X$. Then:

$$
d\left(x_{n}, x_{0}\right) \leq s d\left(x_{0}, x_{1}\right)+\cdots+s^{n-1} d\left(x_{n-2}, x_{n-1}\right)+s^{n-1} d\left(x_{n-1}, x_{n}\right) .
$$

The notion of well-posedness was treated in many articles, for example the article of M. Akkouchi, V. Popa [1] and M. Boriceanu [4].

Definition 3. Let $(X, d)$ be a generalized $b$-metric space and $f, g:(X, d) \rightarrow(X, d)$ be two mappings. The fixed point problem of $f$ and $g$ is said to be well posed if:

i) $f$ and $g$ have a unique common fixed point $z$ in $X$,

ii) for any sequence $\left\{x_{n}\right\}$ in $X$ such that $\lim _{n \rightarrow \infty} d\left(f\left(x_{n}\right), x_{n}\right)=0$ or $\lim _{n \rightarrow \infty} d\left(g\left(x_{n}\right), x_{n}\right)=0$, we have $\lim _{n \rightarrow \infty} d\left(x_{n}, z\right)=0$.

Now, we give this lemma which is a generalization of lemma 3.1 of [12].

Lemma 2. Let $(X, d)$ be a generalized $b$-metric space and $\left\{x_{n}\right\}$ a sequence in $X$ such that

$$
d\left(x_{n}, x_{n+1}\right) \leq C d\left(x_{n-1}, x_{n}\right), \quad n=1,2, \ldots,
$$

where $C \in \mathcal{M}_{n \times n}\left(\mathbb{R}_{+}\right)$. Then the sequence $\left\{x_{n}\right\}$ is Cauchy sequence in $X$ provided that $S C$ is convergent towards zero.

Proof. For any n, we have:

$$
\begin{aligned}
d\left(x_{n}, x_{n+1}\right) & \leq C d\left(x_{n-1}, x_{n}\right) \\
& \leq C^{2} d\left(x_{n-2}, x_{n-1}\right) \leq \ldots \leq C^{n} d\left(x_{0}, x_{1}\right) .
\end{aligned}
$$

To prove that $\left(x_{n}\right)_{n \in \mathbb{N}}$ is a Cauchy sequence, we estimate $d\left(x_{n}, x_{n+p}\right)$ using the triangle inequality:

$$
\begin{aligned}
d\left(x_{n}, x_{n+p}\right) & \leq s d\left(x_{n}, x_{n+1}\right)+s^{2} d\left(x_{n+1}, x_{n+2}\right)+\cdots+s^{p-2} d\left(x_{n+p-3}, x_{n+p-2}\right) \\
& +s^{p-1} d\left(x_{n+p-2}, x_{n+p-1}\right)+s^{p-1} d\left(x_{n+p-1}, x_{n+p}\right) \\
& \leq s C^{n} d\left(x_{0}, x_{1}\right)+s^{2} C^{n+1} d\left(x_{0}, x_{1}\right)+\cdots+s^{p-2} C^{n+p-3} d\left(x_{0}, x_{1}\right) \\
& +s^{p-1} C^{n+p-2} d\left(x_{0}, x_{1}\right)+s^{p-1} C^{n+p-1} d\left(x_{0}, x_{1}\right) \\
& =s C^{n} d\left(x_{0}, x_{1}\right)\left[I+s C+\cdots+s^{p-2} C^{p-2}+s^{p-2} C^{p-1}\right] \\
& \leq s C^{n} d\left(x_{0}, x_{1}\right)\left[I+s C+\cdots+s^{p-2} C^{p-2}+s^{p-1} C^{p-1}\right] \\
& \leq s C^{n} d\left(x_{0}, x_{1}\right)(I-s C)^{-1} \\
& \leq(s C)^{n} d\left(x_{0}, x_{1}\right)(I-s C)^{-1} .
\end{aligned}
$$

Note that $(I-s C)$ is nonsingular since $s C$ is convergent to zero. This implies that the sequence $\left(x_{n}\right)_{n \in \mathbb{N}}$ is a Cauchy sequence.

In the case of $b$-metric space, the previous lemma will be as follows: 
Lemma 3. [12] Let $(X, d)$ be a b-metric space, $\left\{x_{n}\right\}$ a sequence in $X$ such that:

$$
d\left(x_{n}, x_{n+1}\right) \leq C d\left(x_{n-1}, x_{n}\right),
$$

where $0 \leq C<1$. Then the sequence $\left\{x_{n}\right\}$ is a Cauchy sequence in $X$ provided that $s C<1$.

For the case of generalized metric space or metric space it is enough to replace $s$ by 1 in lemma 2 and lemma 3 respectively.

In the next section, we generalize and improve the following theorem of M. Boriceanu [5]:

Theorem 2. Let $(X, d)$ be a complete generalized b-metric space. Assume that the operator $f: X \rightarrow X$ satisfies the following conditions:

(a) $f$ is continuous;

(b) there exists matrices $M, N, P \in \mathcal{M}_{n \times n}\left(\mathbb{R}_{+}\right)$with:

(i) $(I-N-P s)$ is nonsingular and $(I-N-P s)^{-1} \in \mathcal{M}_{n \times n}\left(\mathbb{R}_{+}\right)$;

(ii) $s C$ is convergent towards zero, where $C=(I-N-P s)^{-1}(M+N+$ $P s)$;

(iii) $d(f(x), f(y)) \leq M d(x, y)+N[d(x, f(x))+d(y, f(y))]$ $+P[d(x, f(y))+d(y, f(x))]$, for all $x, y \in X$.

Then:

(1) $f$ has a fixed point $x^{*}$ in $X$.

(2) If, in addition, $(I-M-2 P)$ is nonsingular and $(I-M-2 P)^{-1}$ $\in \mathcal{M}_{n \times n}\left(\mathbb{R}_{+}\right)$, then $x^{*}$ is unique.

\section{COMMON FIXED POINT THEOREMS FOR TWO OPERATORS ON GENERALIZED $b$-METRIC SPACE WITHOUT THE ASSUMPTION OF CONTINUITY}

The first main result of this paper is the following:

Theorem 3. Let $(X, d)$ be a complete generalized b-metric space. Assume that the operators $f, g: X \rightarrow X$ satisfy the following conditions:

there exists matrices $M, N, P \in \mathcal{M}_{n \times n}\left(\mathbb{R}_{+}\right)$with:

(i) $(I-N-P s)$ is nonsingular and $(I-N-P s)^{-1} \in \mathcal{M}_{n \times n}\left(\mathbb{R}_{+}\right)$and $(I-$ $\left.s N-s^{2} P\right)$ is nonsingular and $\left(I-s N-s^{2} P\right)^{-1} \in \mathcal{M}_{n \times n}\left(\mathbb{R}_{+}\right)$;

(ii) $s C$ is convergent towards zero, where $C=(I-N-P s)^{-1}(M+N+P s)$;

(iii) $d(f(x), g(y)) \leq M d(x, y)+N[d(x, f(x))+d(y, g(y))]+P[d(x, g(y))+$ $d(y, f(x))]$, for all $x, y \in X$.

Then:

(1) $f$ and $g$ have a common fixed point $z$ in $X$.

(2) If, in addition, $(I-M-2 P)$ is nonsingular and $(I-M-2 P)^{-1}$ $\in \mathcal{M}_{n \times n}\left(\mathbb{R}_{+}\right)$, then $z$ is unique. 
(3) If $\left(I-s(M+P)-s^{2} P\right)$ is nonsingular and $\left(I-s(M+P)-s^{2} P\right)^{-1}$ $\in \mathcal{M}_{n \times n}\left(\mathbb{R}_{+}\right)$, then the fixed point problem (of $f$ and $g$ ) is well-posed.

Proof. 1. Let $x_{0}$ be some point in $X$, we consider $\left(x_{n}\right)_{n \in \mathbb{N}}$ the sequence of successive approximations for $f$ and $g$, defined by:

$$
\begin{array}{ll}
x_{2 n+1}=f\left(x_{2 n}\right), & n=0,1, \ldots \\
x_{2 n+2}=g\left(x_{2 n+1}\right), & n=0,1, \ldots
\end{array}
$$

We have:

$$
\begin{aligned}
& d\left(x_{2 n}, x_{2 n+1}\right) \\
= & d\left(g\left(x_{2 n-1}\right), f\left(x_{2 n}\right)\right) \\
\leq & M d\left(x_{2 n-1}, x_{2 n}\right)+N\left[d\left(x_{2 n}, f\left(x_{2 n}\right)\right)+d\left(x_{2 n-1}, g\left(x_{2 n-1}\right)\right)\right] \\
+ & P\left[d\left(x_{2 n}, g\left(x_{2 n-1}\right)\right)+d\left(x_{2 n-1}, f\left(x_{2 n}\right)\right)\right] \\
= & M d\left(x_{2 n-1}, x_{2 n}\right)+N\left[d\left(x_{2 n}, x_{2 n+1}\right)+d\left(x_{2 n-1}, x_{2 n}\right)\right]+P d\left(x_{2 n-1}, x_{2 n+1}\right) \\
\leq & M d\left(x_{2 n-1}, x_{2 n}\right)+N\left[d\left(x_{2 n}, x_{2 n+1}\right)+d\left(x_{2 n-1}, x_{2 n}\right)\right] \\
+ & P S\left[d\left(x_{2 n-1}, x_{2 n}\right)+d\left(x_{2 n}, x_{2 n+1}\right)\right]
\end{aligned}
$$

this implies that:

$$
\begin{gathered}
d\left(x_{2 n}, x_{2 n+1}\right) \leq(I-N-P s)^{-1}(M+N+P s) d\left(x_{2 n-1}, x_{2 n}\right) \\
=C d\left(x_{2 n-1}, x_{2 n}\right) .
\end{gathered}
$$

Similarly, we have:

$$
\begin{aligned}
& d\left(x_{2 n+1}, x_{2 n+2}\right) \\
= & d\left(f\left(x_{2 n}\right), g\left(x_{2 n+1}\right)\right) \\
\leq & M d\left(x_{2 n}, x_{2 n+1}\right)+N\left[d\left(x_{2 n}, f\left(x_{2 n}\right)\right)+d\left(x_{2 n+1}, g\left(x_{2 n+1}\right)\right)\right] \\
+ & P\left[d\left(x_{2 n}, g\left(x_{2 n+1}\right)\right)+d\left(x_{2 n+1}, f\left(x_{2 n}\right)\right)\right] \\
= & M d\left(x_{2 n}, x_{2 n+1}\right)+N\left[d\left(x_{2 n}, x_{2 n+1}\right)+d\left(x_{2 n+1}, x_{2 n+2}\right)\right]+P d\left(x_{2 n}, x_{2 n+2}\right) \\
\leq & M d\left(x_{2 n}, x_{2 n+1}\right)+N\left[d\left(x_{2 n}, x_{2 n+1}\right)+d\left(x_{2 n+1}, x_{2 n+2}\right)\right] \\
+ & P s\left[d\left(x_{2 n}, x_{2 n+1}\right)+d\left(x_{2 n+1}, x_{2 n+2}\right)\right] .
\end{aligned}
$$

Thus

$$
\begin{gathered}
d\left(x_{2 n+1}, x_{2 n+2}\right) \\
\leq(I-N-P s)^{-1}(M+N+P s) d\left(x_{2 n}, x_{2 n+1}\right)=C d\left(x_{2 n}, x_{2 n+1}\right) .
\end{gathered}
$$

We obtain that:

$$
d\left(x_{n}, x_{n+1}\right) \leq C^{n} d\left(x_{0}, x_{1}\right), \quad \text { for each } n \in \mathbb{N} .
$$


Following the same steps of lemma 2, we get that $\left(x_{n}\right)_{n \in \mathbb{N}}$ is a Cauchy sequence. Using the fact that $(X, d)$ is complete we get that $\left(x_{n}\right)_{n \in \mathbb{N}}$ is convergent in $X$. Thus, there exists $z \in X$ such that $d\left(x_{n}, z\right) \rightarrow 0$, as $n \rightarrow \infty$.

Now, we show that $z$ is a fixed point for $f$ by esteeming $d(f(z), z)$ we obtain:

$$
\begin{aligned}
d(f(z), z) & \leq s d\left(f(z), g\left(x_{2 n+1}\right)\right)+s d\left(x_{2 n+2}, z\right) \\
d(f(z), z)-s d\left(x_{2 n+2}, z\right) & \leq s d\left(f(z), g\left(x_{2 n+1}\right)\right)
\end{aligned}
$$

and

$$
\begin{aligned}
d\left(f(z), g\left(x_{2 n+1}\right)\right) & \leq M d\left(z, x_{2 n+1}\right)+N\left[d(z, f(z))+d\left(x_{2 n+1}, g\left(x_{2 n+1}\right)\right)\right] \\
& +P\left[d\left(z, g\left(x_{2 n+1}\right)\right)+d\left(x_{2 n+1}, f(z)\right)\right] \\
& =M d\left(z, x_{2 n+1}\right)+N\left[d(z, f(z))+d\left(x_{2 n+1}, x_{2 n+2}\right)\right] \\
& +P\left[d\left(z, x_{2 n+2}\right)+d\left(x_{2 n+1}, f(z)\right)\right] .
\end{aligned}
$$

We obtain:

$$
\begin{aligned}
d(f(z), z)-s d\left(x_{2 n+2}, z\right) & \leq s M d\left(z, x_{2 n+1}\right)+s N\left[d(z, f(z))+d\left(x_{2 n+1}, x_{2 n+2}\right)\right] \\
& +s P\left[d\left(z, x_{2 n+2}\right)+s\left(d\left(x_{2 n+1}, z\right)+d(z, f(z))\right)\right]
\end{aligned}
$$

Passing to the limit and taking into account that $\left(I-s N-s^{2} P\right)$ is nonsingular and $\left(I-s N-s^{2} P\right)^{-1} \in \mathcal{M}_{n \times n}\left(\mathbb{R}_{+}\right)$we get that $z$ is a fixed point for $f$.

Let us show that $g(z)=z$ using the condition (iii), we have:

$$
\begin{aligned}
d(z, g(z)) & =d(f(z), g(z)) \\
& \leq M d(z, z)+N[d(z, f(z))+d(z, g(z))]+P[d(z, g(z))+d(z, f(z))] .
\end{aligned}
$$

We obtain:

$$
(I-N-P) d(z, g(z)) \leq 0 .
$$

Note that $(I-N-P)$ is nonsingular and $(I-N-P)^{-1} \in \mathcal{M}_{n \times n}\left(\mathbb{R}_{+}\right)$we conclude that $z=g(z)$ so we obtain that $z$ is a common fixed point for $f$ and $g$.

2. Now, we show that $f$ and $g$ have a unique common fixed point. For this, we assume that there exists another point $w$ fixed by $f$. Using the condition (iii), we have:

$$
\begin{aligned}
d(w, z) & =d(f(w), g(z)) \\
& \leq M d(w, z)+N[d(w, f(w))+d(z, g(z))]+P[d(w, g(z))+d(z, f(w))] \\
& \leq(M+2 P) d(w, z) .
\end{aligned}
$$

We obtain:

$$
(I-M-2 P) d(w, z) \leq 0 .
$$

Taking into account that $(I-M-2 P)$ is nonsingular and $(I-M-2 P)^{-1}$ $\in \mathcal{M}_{n \times n}\left(\mathbb{R}_{+}\right)$this implies that $z$ is a unique common fixed point for $f$ and $g$. 
3. From the previous results, we know that $f$ and $g$ have a unique common fixed point $z$ in $X$. Let $\left(x_{n}\right)_{n \in \mathbb{N}}$ be a sequence of points in $X$ such that $\lim _{n \rightarrow \infty} d\left(f\left(x_{n}\right), x_{n}\right)=$ 0 or $\lim _{n \rightarrow \infty} d\left(g\left(x_{n}\right), x_{n}\right)=0$, we have:

$$
d\left(x_{n}, z\right) \leq s\left(d\left(x_{n}, g\left(x_{n}\right)\right)+d\left(g\left(x_{n}\right), f(z)\right)\right)
$$

and

$$
\begin{aligned}
& d\left(g\left(x_{n}\right), f(z)\right) \\
\leq & M d\left(x_{n}, z\right)+N\left[d\left(x_{n}, g\left(x_{n}\right)\right)+d(z, f(z))\right]+P\left[d\left(x_{n}, f(z)\right)+d\left(z, g\left(x_{n}\right)\right)\right] \\
\leq & M d\left(x_{n}, z\right)+N d\left(x_{n}, g\left(x_{n}\right)\right)+P d\left(x_{n}, z\right)+P s\left[d\left(z, x_{n}\right)+d\left(x_{n}, g\left(x_{n}\right)\right)\right]
\end{aligned}
$$

we obtain:

$$
\begin{aligned}
d\left(x_{n}, z\right) & \leq s d\left(x_{n}, g\left(x_{n}\right)\right)+s\left[M d\left(x_{n}, z\right)+N d\left(x_{n}, g\left(x_{n}\right)\right)+P d\left(x_{n}, z\right)\right. \\
& \left.+P s\left(d\left(z, x_{n}\right)+d\left(x_{n}, g\left(x_{n}\right)\right)\right)\right] .
\end{aligned}
$$

This implies that:

$$
\left(I-s(M+P)-s^{2} P\right) d\left(z, x_{n}\right) \leq\left(s I+s N+s^{2} P\right) d\left(x_{n}, g\left(x_{n}\right)\right) .
$$

Passing to the limit and taking into account that $\left(I-s(M+P)-s^{2} P\right)$ is nonsingular and $\left(I-s(M+P)-s^{2} P\right)^{-1} \in \mathcal{M}_{n \times n}\left(\mathbb{R}_{+}\right)$, we get that $d\left(z, x_{n}\right) \rightarrow 0$, as $n \rightarrow \infty$.

We get the concept of generalized metric space in the previous theorem if $s=1$, in this case we have:

Corollary 1. Let $(X, d)$ be a complete generalized metric space. Assume that the operators $f, g: X \rightarrow X$ satisfy the following conditions:

there exists matrices $M, N, P \in \mathcal{M}_{n \times n}\left(\mathbb{R}_{+}\right)$with:

(i) $(I-N-P)$ is nonsingular and $(I-N-P)^{-1} \in \mathcal{M}_{n \times n}\left(\mathbb{R}_{+}\right)$;

(ii) $C$ is convergent towards zero, where $C=(I-N-P)^{-1}(M+N+P)$;

(iii) $d(f(x), g(y)) \leq M d(x, y)+N[d(x, f(x))+d(y, g(y))]+P[d(x, g(y))$ $+d(y, f(x))]$, for all $x, y \in X$.

Then:

(1) $f$ and $g$ have a common fixed point $z$ in $X$.

(2) If, in addition, $(I-M-2 P)$ is nonsingular and $(I-M-2 P)^{-1}$ $\in \mathcal{M}_{n \times n}\left(\mathbb{R}_{+}\right)$, then

- $z$ is unique.

- The fixed point problem (of $f$ and $g$ ) is well-posed.

Proof. As in the lemma 2, we have:

$$
d\left(x_{n}, x_{n+p}\right) \leq C^{n} d\left(x_{0}, x_{1}\right)(I-C)^{-1} .
$$

Note that $(I-C)$ is nonsingular since $C$ is convergent to zero. This implies that the sequence $\left(x_{n}\right)_{n \in \mathbb{N}}$ is a Cauchy sequence. Using the fact that $(X, d)$ is complete we 
get that $\left(x_{n}\right)_{n \in \mathbb{N}}$ is convergent in $X$. Thus, there exists $z \in X$ such that $d\left(x_{n}, z\right) \rightarrow 0$, as $n \rightarrow \infty$.

Now, we show that $\mathrm{z}$ is a fixed point for $f$ for all positive integers $n$, using the condition (iii) we have:

$$
\begin{aligned}
d\left(f(z), x_{2 n+2}\right) & =d\left(f(z), g\left(x_{2 n+1}\right)\right) \\
& \leq M d\left(z, x_{2 n+1}\right)+N\left[d(z, f(z))+d\left(x_{2 n+1}, g\left(x_{2 n+1}\right)\right)\right] \\
& +P\left[d\left(z, g\left(x_{2 n+1}\right)\right)+d\left(x_{2 n+1}, f(z)\right)\right] \\
& =M d\left(z, x_{2 n+1}\right)+N\left[d(z, f(z))+d\left(x_{2 n+1}, x_{2 n+2}\right)\right] \\
& +P\left[d\left(z, x_{2 n+2}\right)+d\left(x_{2 n+1}, f(z)\right)\right] .
\end{aligned}
$$

Passing to the limit (the generalized metric function $d$ is continuous) and taking into account that $(I-N-P)$ is nonsingular and $(I-N-P)^{-1} \in \mathcal{M}_{n \times n}\left(\mathbb{R}_{+}\right)$this implies that $z=f(z)$, so $z$ is a fixed point for $f$.

The rest of the proof follows as in theorem 3 .

If $n=1$ in the previous theorem then we get the concept of $b$-metric introduced by Bakhtin, in this case we have:

Corollary 2. Let $(X, d)$ be a complete b-metric space. Assume that the operators $f, g: X \rightarrow X$ satisfy the following conditions:

there exists constants $M, N, P \in \mathbb{R}_{+}$with:

(i) $d(f(x), g(y)) \leq M d(x, y)+N[d(x, f(x))+d(y, g(y))]+P[d(x, g(y))+$ $d(y, f(x))]$, for all $x, y \in X$;

(ii) $s C<1$ with $C=\frac{M+N+P s}{1-N-P s}, s N+s^{2} P<1$ and $N+P s<1$.

Then:

(1) $f$ and $g$ have a common fixed point $z$ in $X$.

(2) If, in addition, $M+2 P<1$ then $z$ is unique.

(3) If $\left(s(M+P)+s^{2} P\right)<1$, then the fixed point problem (of $f$ and $g$ ) is wellposed.

Proof. Applying lemma 3 (we can also see [7,12] and following the same steps as in theorem 3, we get our results.

Next, We give the definition of a $b$-normed vector space.

Definition 4. Let $X$ be a vector space. A $b$-norm on $X$ is a function:

$$
\|.\|: X \rightarrow \mathbb{R}_{+}
$$

that satisfies the following three conditions:

(1) $\|x\|=0 \Leftrightarrow x=0, \quad \forall x \in X$;

(2) $\|\alpha x\|=|\alpha|^{s}\|x\|, \quad \forall x \in X, \forall \alpha \in \mathbb{R}$ and $s \geq 1$;

(3) $\|x+y\| \leq s(\|x\|+\|y\|), \quad \forall x, y \in X, s \geq 1$. 
A vector space equipped with a $b$-norm is called a $b$-normed vector space.

Remark 2. Let us notice here that some advantages of a vector-valued norm with respect to the usual scalar norms were very nice pointed out, by several examples, see [10]. More precisely, one can show that, in general, the condition that $C$ is a matrix convergent to zero is weaker than the contraction conditions for operators given in terms of the scalar norms on $X$ of the following type:

$$
\begin{aligned}
\|x\|_{M} & =\left\|x_{1}\right\|+\left\|x_{2}\right\| \\
\|x\|_{C} & =\max \left\{\left\|x_{1}\right\|,\left\|x_{2}\right\|\right\} \\
\|x\|_{E} & =\left(\left\|x_{1}\right\|^{2}+\left\|x_{2}\right\|^{2}\right)^{1 / 2}
\end{aligned}
$$

As an application of theorem 3, we present this theorem for a system of operator equations.

Theorem 4. Let $(X,||$.$) be a b-normed complete vector space and let f, g: X \times$ $X \rightarrow X$ be two operators. Suppose that there exist $m_{i j}, n_{i j}, p_{i j} \in \mathbb{R}_{+}, i, j \in\{1,2\}$ such that,

$$
M=\left(\begin{array}{ll}
m_{11} & m_{12} \\
m_{21} & m_{22}
\end{array}\right), N=\left(\begin{array}{ll}
n_{11} & n_{12} \\
n_{21} & n_{22}
\end{array}\right), P=\left(\begin{array}{ll}
p_{11} & p_{12} \\
p_{21} & p_{22}
\end{array}\right)
$$

for each $x=\left(x_{1}, x_{2}\right), y=\left(y_{1}, y_{2}\right) \in X \times X$, one has:

$$
\begin{aligned}
& \left|f_{1}\left(x_{1}, x_{2}\right)-g_{1}\left(y_{1}, y_{2}\right)\right| \leq m_{11}\left|x_{1}-y_{1}\right|+m_{12}\left|x_{2}-y_{2}\right| \\
& \quad+n_{11}\left(\left|x_{1}-f_{1}\left(x_{1}, x_{2}\right)\right|+\left|y_{1}-g_{1}\left(y_{1}, y_{2}\right)\right|\right) \\
& \quad+n_{12}\left(\left|x_{2}-f_{2}\left(x_{1}, x_{2}\right)\right|+\left|y_{2}-g_{2}\left(y_{1}, y_{2}\right)\right|\right) \\
& \quad+p_{11}\left(\left|x_{1}-g_{1}\left(y_{1}, y_{2}\right)\right|+\left|y_{1}-f_{1}\left(x_{1}, x_{2}\right)\right|\right) \\
& \quad+p_{12}\left(\left|x_{2}-g_{2}\left(y_{1}, y_{2}\right)\right|+\left|y_{2}-f_{2}\left(x_{1}, x_{2}\right)\right|\right)
\end{aligned}
$$

$$
\begin{aligned}
& \left|f_{2}\left(x_{1}, x_{2}\right)-g_{2}\left(y_{1}, y_{2}\right)\right| \leq m_{21}\left|x_{1}-y_{1}\right|+m_{22}\left|x_{2}-y_{2}\right| \\
& \quad+n_{21}\left(\left|x_{1}-f_{1}\left(x_{1}, x_{2}\right)\right|+\left|y_{1}-g_{1}\left(y_{1}, y_{2}\right)\right|\right) \\
& \quad+n_{22}\left(\left|x_{2}-f_{2}\left(x_{1}, x_{2}\right)\right|+\left|y_{2}-g_{2}\left(y_{1}, y_{2}\right)\right|\right) \\
& \quad+p_{21}\left(\left|x_{1}-g_{1}\left(y_{1}, y_{2}\right)\right|+\left|y_{1}-f_{1}\left(x_{1}, x_{2}\right)\right|\right) \\
& \quad+p_{22}\left(\left|x_{2}-g_{2}\left(y_{1}, y_{2}\right)\right|+\left|y_{2}-f_{2}\left(x_{1}, x_{2}\right)\right|\right) .
\end{aligned}
$$

In addition, we assume that the matrix $(I-N-P s)$ is nonsingular and $(I-N-$ $P s)^{-1} \in \mathcal{M}_{n \times n}\left(\mathbb{R}_{+}\right),\left(I-s N-s^{2} P\right)$ is nonsingular and $\left(I-s N-s^{2} P\right)^{-1} \in$ $\mathcal{M}_{n \times n}\left(\mathbb{R}_{+}\right)$and $s C$ is convergent to zero.

Then, the system

$$
\begin{aligned}
& u_{1}=f_{1}\left(u_{1}, u_{2}\right)=g_{1}\left(u_{1}, u_{2}\right), \\
& u_{2}=f_{2}\left(u_{1}, u_{2}\right)=g_{2}\left(u_{1}, u_{2}\right),
\end{aligned}
$$


has at least one solution $z \in X \times X$. Moreover, if, in addition, the matrix ( $I-M-$ $2 P)$ is nonsingular and $(I-M-2 P)^{-1} \in \mathcal{M}_{n \times n}\left(\mathbb{R}_{+}\right)$, then the above solution is unique.

Proof. Consider $E=X \times X$ and the operators $f, g$ given by the expression:

$$
\begin{aligned}
& f\left(x_{1}, x_{2}\right)=\left(f_{1}\left(x_{1}, x_{2}\right), f_{2}\left(x_{1}, x_{2}\right)\right) \\
& g\left(y_{1}, y_{2}\right)=\left(g_{1}\left(y_{1}, y_{2}\right), g_{2}\left(y_{1}, y_{2}\right)\right) .
\end{aligned}
$$

Then our system is now represented as a fixed point equation of the following form: $w=f(w)=g(w), w \in E$. Notice also that the conditions (1)+(2) can be jointly represented as follows:

$$
\begin{aligned}
\|f(x)-g(y)\| \leq & M\|x-y\|+N(\|x-f(x)\|+\|y-g(y)\|) \\
& +P(\|x-g(y)\|+\|y-f(x)\|) \text { for all } x, y \in X \times X .
\end{aligned}
$$

Hence, theorem 3 applies in $(E, d)$ with $d(u, v)=\|u-v\|=\left(\begin{array}{l}\left|u_{1}-v_{1}\right| \\ \left|u_{2}-v_{2}\right|\end{array}\right)$.

\section{FIXED POINT THEOREMS FOR TWO OPERATORS ON GENERALIZED $b$-METRIC SPACE WITH TWO $b$-METRICS}

The next result improves this theorem of M. Boriceanu[5]:

Theorem 5. Let $(X, \delta)$ be a complete generalized $b$-metric space and $d$ another vector-valued $b$-metric on $X$. Assume that the operator $f: X \rightarrow X$ satisfies the following conditions:

(a) $f$ is $(d, \delta)$-uniformly continuous or there exists a matrix $U \in \mathcal{M}_{n \times n}\left(\mathbb{R}_{+}\right)$ such that $\delta(x, y) \leq U \cdot d(x, y)$, for all $x, y \in X$;

(b) $f$ is $(\delta, \delta)$-continuous;

(c) there exists matrices $M, N, P \in \mathcal{M}_{n \times n}\left(\mathbb{R}_{+}\right)$with:

(i) $(I-N-P s)$ is nonsingular and $(I-N-P s)^{-1} \in \mathcal{M}_{n \times n}\left(\mathbb{R}_{+}\right)$;

(ii) $s C$ is convergent towards zero, where $C=(I-N-P s)^{-1}(M+N+$ $P s)$;

(iii) $d(f(x), f(y)) \leq M d(x, y)+N[d(x, f(x))+d(y, f(y))]$ $+P[d(x, f(y))+d(y, f(x))]$, for all $x, y \in X$.

Then:

(1) For any $x_{0} \in X$ we have $\delta\left(f^{k}\left(x_{0}, x^{*}\right) \rightarrow 0\right.$, as $k \rightarrow \infty$, where $x^{*}$ is a fixed point for $f$.

(2) If, in addition, $(I-M-2 P)$ is nonsingular and $(I-M-2 P)^{-1}$ $\in \mathcal{M}_{n \times n}\left(\mathbb{R}_{+}\right)$, then $x^{*}$ is unique.

In this section, we present another result in the case of a generalized $b$-metric space but endowed with two $b$-metrics. 
Theorem 6. Let $(X, \delta)$ be a complete generalized $b$-metric space and $d$ another vector-valued $b$-metric on $X$. Assume that the operators $f, g: X \rightarrow X$ satisfy the following conditions:

(a) There exists a matrix $U \in \mathcal{M}_{n \times n}\left(\mathbb{R}_{+}\right)$such that $\delta(x, y) \leq U \cdot d(x, y)$, for all $x, y \in X$;

(b) $f$ is $(\delta, \delta)$-continuous;

(c) There exists matrices $M, N, P \in \mathcal{M}_{n \times n}\left(\mathbb{R}_{+}\right)$with:

(i) $(I-N-P s)$ is nonsingular and $(I-N-P s)^{-1} \in \mathcal{M}_{n \times n}\left(\mathbb{R}_{+}\right)$;

(ii) $s C$ is convergent towards zero, where $C=(I-N-P s)^{-1}(M+N+P s)$

(iii) $d(f(x), g(y)) \leq M d(x, y)+N[d(x, f(x))+d(y, g(y))]$ $+P[d(x, g(y))+d(y, f(x))]$, for all $x, y \in X$.

Then:

(1) $f$ and $g$ have a common fixed point $z$ in $X$.

(2) If, in addition, $(I-M-2 P)$ is nonsingular and $(I-M-2 P)^{-1}$ $\in \mathcal{M}_{n \times n}\left(\mathbb{R}_{+}\right)$, then $z$ is a unique common fixed point of $f$ and $g$.

(3) If $\left(I-s(M+P)-s^{2} P\right)$ is nonsingular and $\left(I-s(M+P)-s^{2} P\right)^{-1} \in$ $\mathcal{M}_{n \times n}\left(\mathbb{R}_{+}\right)$, then the fixed point problem (of $f$ and $g$ ) is well-posed.

Proof. As in the proof of theorem 3, we obtain that $\left(x_{n}\right)_{n \in \mathbb{N}}$ is $d$-Cauchy. It follows from (a) that $\left(x_{n}\right)_{n \in \mathbb{N}}$ is $\delta$-Cauchy sequence. Since $(X, \delta)$ is a complete generalized $b$-metric space, there exists $z \in X$ such that $\delta\left(x_{2 n+1}, z\right) \rightarrow 0$, as $n \rightarrow \infty$.

By (b), we have that $\delta\left(f\left(x_{2 n}\right), f(z)\right) \rightarrow 0$, as $n \rightarrow \infty$. But $\delta\left(f\left(x_{2 n}\right), f(z)\right)=$ $\delta\left(x_{2 n+1}, f(z)\right)$. Hence we have $z=f(z)$. Thus $z$ is a fixed point for $f$ and

$$
\delta\left(f^{n}\left(x_{0}\right), z\right) \rightarrow 0, \text { as } n \rightarrow \infty .
$$

The rest of the proof follows as in theorem 3 .

Now, we present the previous theorem in the case of generalized metric space.

Corollary 3. Let $(X, \delta)$ be a complete generalized metric space and $d$ another vector-valued metric on $X$. Assume that the operators $f, g: X \rightarrow X$ satisfy the following conditions:

(a) There exists a matrix $U \in \mathcal{M}_{n \times n}\left(\mathbb{R}_{+}\right)$such that $\delta(x, y) \leq U$. $d(x, y)$, for all $x, y \in X$;

(b) $f$ is $(\delta, \delta)$-continuous;

(c) there exists matrices $M, N, P \in \mathcal{M}_{n \times n}\left(\mathbb{R}_{+}\right)$with:

(i) $(I-N-P)$ is nonsingular and $(I-N-P)^{-1} \in \mathcal{M}_{n \times n}\left(\mathbb{R}_{+}\right)$;

(ii) $C$ is convergent toward zero, where $C=(I-N-P)^{-1}(M+N+P)$

(iii) $d(f(x), g(y)) \leq M d(x, y)+N[d(x, f(x))+d(y, g(y))]$ $+P[d(x, g(y))+d(y, f(x))]$, for all $x, y \in X$.

Then : 
(1) $z$ is a common fixed point for $f$ and $g$.

(2) If, in addition, $(I-M-2 P)$ is nonsingular and $(I-M-2 P)^{-1}$ $\in \mathcal{M}_{n \times n}\left(\mathbb{R}_{+}\right)$, then

- $z$ is a unique common fixed point of $f$ and $g$.

- The fixed point problem (of $f$ and $g$ ) is well-posed.

\section{ACKNOWLEDGEMENT}

The first author was supported in part by the research project CNEPRU, Grant No. B01520130004. The third author was partially supported by the research project CNEPRU with grant number (B01520130004).

\section{REFERENCES}

[1] M. Akkouchi and V. Popa, "Well-posedness of fixed point problem for mappings satisfying an implicit relation," Demonstratio Math., vol. 43, no. 4, pp. 923-929, 2010.

[2] I. A. Bakhtin, "The contraction mapping principle in almost metric space," pp. 26-37, 1989.

[3] V. Berinde, Seminar on Fixed Point Theory, ser. Preprint, I. A. Rus, Ed. "Babeş-Bolyai" University, Faculty of Mathematics and Computer Science, Cluj-Napoca, 1993, vol. 93.

[4] M. Boriceanu, "Fixed point theory for multivalued generalized contraction on a set with two $b$ metrics," Stud. Univ. Babeş-Bolyai Math., vol. 54, no. 3, pp. 3-14, 2009.

[5] M. Boriceanu, "Fixed point theory on spaces with vector-valued $b$-metrics," Demonstratio Math., vol. 42, no. 4, pp. 831-841, 2009, doi: 10.1515/dema-2013-0198.

[6] S. Czerwik, "Nonlinear set-valued contraction mappings in b-metric spaces," Atti Sem. Mat. Fis. Univ. Modena, vol. 46, no. 2, pp. 263-276, 1998.

[7] H. Huang and S. Xu, "Fixed point theorems of contractive mappings in cone $b$-metric spaces and applications," Fixed Point Theory Appl., pp. 2013:112, 10, 2013, doi: 10.1186/1687-1812-2013112. [Online]. Available: http://dx.doi.org/10.1186/1687-1812-2013-112

[8] N. Hussain, D. Dorić, Z. Kadelburg, and S. Radenović, "Suzuki-type fixed point results in metric type spaces," Fixed Point Theory Appl., pp. 2012:126, 12, 2012, doi: 10.1186/1687-1812-2012126. [Online]. Available: http://dx.doi.org/10.1186/1687-1812-2012-126

[9] A. I. Perov, "On the cauchy problem for a system of ordinary differential equations," Pviblizhen. Met. Reshen. Differ. Uvavn, vol. 2, pp. 115-134, 1964.

[10] R. Precup, "The role of matrices that are convergent to zero in the study of semilinear operator systems," Math. Comput. Modelling, vol. 49, no. 3-4, pp. 703-708, 2009, doi: 10.1016/j.mcm.2008.04.006. [Online]. Available: http://dx.doi.org/10.1016/j.mcm.2008.04.006

[11] I. A. Rus, "Some metrical fixed point theorems," Studia Univ. Babeş-Bolyai Math., vol. 24, no. 1, pp. 73-77, 1979.

[12] S. L. Singh, S. Czerwik, K. Król, and A. Singh, "Coincidences and fixed points of hybrid contractions,” Tamsui Oxf. J. Math. Sci., vol. 24, no. 4, pp. 401-416, 2008.

[13] M. Turinici, "Finite-dimensional vector contractions and their fixed points," Studia Univ. BabeşBolyai Math., vol. 35, no. 1, pp. 30-42, 1990.

[14] R. S. Varga, Matrix iterative analysis, expanded ed., ser. Springer Series in Computational Mathematics. Springer-Verlag, Berlin, 2000, vol. 27. [Online]. Available: http://dx.doi.org/10. 1007/978-3-642-05156-2. doi: 10.1007/978-3-642-05156-2 
Authors' addresses

\section{S. Bazine}

University of Larbi Ben M'Hidi, Department of Mathematics, 04000, Oum El Bouaghi, Algeria E-mail address: bazine-safia@hotmail.fr

A. Aliouche

University of Larbi Ben M'Hidi, Department of Mathematics, 04000, Oum El Bouaghi, Algeria

E-mail address: alioumath@yahoo.fr

\section{F. Ellaggoune}

University of 8 Mai 1945, Department of Mathematics, P. O. Box 401, 24000 Guelma, Algeria

E-mail address: fellaggoune@gmail.com 